\title{
Life Course Racism and Depressive Symptoms among Young Black Women
}

\author{
Arbor J L Quist · Xiaoxia Han · Donna D Baird · \\ Lauren A Wise · Ganesa Wegienka • \\ Cheryl L Woods-Giscombe · Anissa Irvin Vines
}

Accepted: 16 August 2021 / Published online: 15 January 2022

(C) The New York Academy of Medicine 2021

\begin{abstract}
The objective of this study is to evaluate the life course effects of racism on depressive symptoms in young Black women and to identify particularly sensitive periods. Guided by life-course theory and using logistic regression, we analyzed baseline data on racism frequency and stress from racism at two time periods (before age 20 and during the 20s) and follow-up data (at approximate 20-month intervals) on depressive symptoms (using a modified 11-item Center for Epidemiologic Studies Depression Scale, CES-D) among 1612 Black women participants aged 23-34 years living in Detroit, MI. Of
\end{abstract}

\footnotetext{
A. J. L. Quist · A. I. Vines ( $\square)$

Department of Epidemiology, Gillings School of Global Public Health, University of North Carolina at Chapel Hill, Chapel Hill, NC, USA

e-mail: avines@email.unc.edu

X. Han $\cdot$ G. Wegienka

Department of Public Health Sciences, Henry Ford Health

System, Detroit, MI, USA

D. D. Baird

Epidemiology Branch, Women's Health Group,

National Institute for Environmental Health Sciences,

Research Triangle, NC, USA

L. A. Wise

Department of Epidemiology, Boston University School of Public Health, Boston, MA, USA

C. L. Woods-Giscombe

School of Nursing, University of North Carolina at Chapel

Hill, Chapel Hill, NC, USA
}

the 1612 women, $65 \%$ reported experiencing some racism at baseline, and $36.5 \%$ had high depressive symptoms at follow-up. Those who experienced high frequency of racism before age 20 had an increased risk for high depressive symptoms $(\mathrm{RR}=1.26,95 \%$ CI: $1.07,1.46)$ compared to participants in the low racism frequency group. We observed similar associations for high vs. low stress from racism $(\mathrm{RR}=1.30$, 95\% CI: 1.06, 1.54) and high vs. low combination of racism frequency and stress $(\mathrm{RR}=1.38,95 \% \mathrm{CI}$ : $1.13,1.64)$. These findings did not hold or were weaker when assessing racism during the 20s. Among women who experienced high racism across the two time periods, the risk of high depressive symptoms was higher than those who experienced low racism during both periods $(\mathrm{RR}=1.49,95 \% \mathrm{CI}: 1.14,1.86)$. The slightly stronger associations between racism and depressive symptoms in childhood and adolescence than in young adulthood suggest that early life might be a sensitive period for experiencing racism.

Keywords Depression - Racism - Discrimination · Social support $\cdot$ Mental health $\cdot$ Life course

\section{Introduction}

In 2017, approximately 17.3 million adults in the USA had at least one major depressive episode, with adult women having a higher prevalence $(8.7 \%)$ compared with men (5.3\%) [1]. Depression and depressive 
symptoms can diminish psychological well-being, physical health, and quality of life [2, 3]. Depression among Black people is often underreported, underdiagnosed, and undertreated [4]. Studies have shown that racism is an important contributing factor to poor mental health outcomes among Black adolescents, pregnant women, and older women [5-9].

"Racism is a system of structuring opportunity and assigning value based on phenotype (i.e., race) that unfairly disadvantages some individuals and communities, unfairly advantages other individuals and communities, and undermines the realization of the full potential of the whole society through a waste of human resources"(10, page 4). Racism operates at three levels-institutionalized racism, personally mediated racism, and internalized racism-to create the racial climate [11]. Despite more than two decades of accumulating discourse and research on racism as a social determinant of health or a fundamental cause of health and health disparities by scientists and practitioners in the field of public health, [12, 13] progress towards elucidating the mechanisms of its impact on health and well-being has fallen short as well as the political and societal will to bring forth overdue change [14-17].

Recent events in the USA have highlighted the persistence and pervasiveness of racism, especially institutionalized racism which is defined as the "structures, policies, practices, and norms resulting in differential access to the goods, services, and opportunities of society by race," whereby race is a social construct that shapes the daily realities of Black communities as well as other communities of color (10, p. 4). Heightened attention from media outlets reporting daily news on the SARS-CoV-2 pandemic created opportunity for people worldwide to glimpse the lived and intergenerational realities of Black Americans. First, the disproportionate number of deaths due to COVID-19 on Black and Brown communities aimed a spotlight on the persisting health disparities, and more importantly, highlighted unequal access to health, social, and human services [18]. Additionally, the murder of George Floyd served as another wakeup call that racism in America remains a salient and engrained system despite centuries of civil movements for change. Eliminating institutionalized racism is essential for individuals to achieve their maximum health and well-being, but research has also shown the deleterious effects of racism at the interpersonal level on the mental health status of Black people [5, 19-23]. Furthermore, interpersonal/perceived racism defined as unfair treatment experienced by members of marginalized racial and ethnic groups has been identified as a chronic stressor that can have a negative effect on mental and physical health[21, 24]. Racism may function differently from other social stressors, as it may cause traumatic stress responses from its unpredictable, painful, and continual nature [21, 25-27].

The biological effects of racism may vary from adolescence to adulthood [24, 26]. Specifically, adolescents and young adults who perceive racism are at greater risk of adverse mental health outcomes than older adults.[24] A 2009 meta-analysis of 110 articles found that racial discrimination increases stress responses and negatively affects mental health.[21] Additional studies have also reported that social support, religious community, and financial security lessen the impact of the stress of discrimination on mental health, [21, 28-30] while other studies did not find this modifying effect [5, 21, 31].

Several studies have found an association between perceived racism and depression/depressive symptoms, [5, 19-23] but the inconsistency of results regarding modifiers and the lack of stress assessment over the life course in majority of racism studies highlight remaining knowledge gaps in the field. The bulk of the discrimination research has been crosssectional [5, 20, 21, 25]. There is growing interest in life-course theory and the various models (e.g., critical period, transitions, accumulation) to understand mental health disparities [19, 32-34]. One study used life-course theory to examine the frequency of discrimination events and depressive symptoms among 296 Black men in Nashville, TN, across the adult life course [19]. They found the frequency of everyday discrimination events (e.g., interpersonal insults and hassles due to racism), but not the frequency of major discrimination events (e.g., discrimination in the housing market, labor market, criminal justice system), was associated with depressive symptoms. Most recently, a study examining trajectories or the transitions in experiences of racial discrimination from emerging adulthood (i.e., 18-25 years) to adulthood found that Black people in the moderatedeclining trajectory had higher levels of depressive symptoms and other indicators of poor psychological well-being than the low-stable racism trajectory 
[35]. Additionally, a longitudinal study of 343 women in Detroit found that an increase in self-reported discrimination frequency over time was associated with an increase in depressive symptoms over time [23]. Neither study included an assessment of stress appraisal, which is the degree to which the experience of discrimination gets evaluated as stressful by the respondent. Because an individual's appraisal of situations influences the related stress response, participants' subjective stress levels from racism may be related to their mental health $[36,37]$.

The goals of the current analyses are to understand the influence of racism at critical developmental periods of childhood to adolescence (before age 20) and early adulthood (during the twenties) on later depressive symptoms among young Black women aged 23-35 years. More specifically, our goals are to: (1) describe racism with respect to reported frequency of the exposure, the degree of stress it caused, and examine the effect of these two factors individually and in combination for each time period; (2) investigate life-course patterns of racist exposures over time to assess their influences on depressive symptoms; and (3) assess the potential for modifying (buffering) effects of a supportive environment in childhood and social support during adult life on the association between life-course racism and depressive symptoms.

\section{Methods}

We used data from the Study of Environment, Lifestyle, and Fibroids (SELF) which enrolled 1693 volunteer women aged 23-35 years between 2010 and 2012 who self-identified as at least part Black or African American with an intact uterus and resided in the Detroit, MI, area. Participants completed three follow-up data collection points after baseline over 5 years at approximate 20-month intervals. Details about the eligibility criteria, recruitment process, and the data collected for this study have been described elsewhere [38]. SELF was established as a prospective study among Black women to examine fibroid development and associated environmental and lifestyle factors; this current investigation includes participants enrolled in the study who answered questions on depressive symptoms and experiences with racism, regardless of their uterine fibroid status.
Assessment of Racism

At study baseline, participants answered questions about their experience(s) of racism during two time periods: before the age of 20 (BF20) and during their twenties (DUR20s) using the Past Experiences of Racism subscale of the Telephone-administered Perceived Racism Scale (TPRS) [39]. For each time period ("BF20" and "DUR20s"), the frequency of each respondent's experience was assessed with the question, "How often did you experience racism?" with the response options of never, rarely, some of the time, and most of the time. Frequency of racism was categorized as never, low, and high, where high reflects the combined levels of "some of the time" and "most of the time," due to small numbers. Participants who reported a frequency of racism other than "never" were then asked, "How stressful would you describe those experiences?" The stress of racism was then categorized as follows: no stress (not stressful), low stress (mildly stressful, the referent group), and high stress (moderately stressful and severely stressful were combined due to small numbers). We assessed associations with depressive symptoms for frequency of racism and stress of racism separately at each time period.

Furthermore, we created a "Frequency and Stress" racism variable based on the cross-tabulation of the frequency of and the stress of racism variables to create categories reflecting levels of effect in the intensity of the two factors: (1) Never — "no experience of racism"; (2) Low - "rarely experienced racism and reported not stressful"; (3) Moderate - "rarely experienced racism and reported at least mildly stressful" or "experienced racism some or most of the time and reported not stressful"; and (4) High - "experienced racism some or most of the time and reported at least mildly stressful." "Low Frequency and Stress" was the reference category in all models because of the large size of this group and because individuals who report "Never" may be a unique group regarding to their view and lived experiences with regard to racism in comparison to those who report at least some degree of exposure.

Two life-course models - critical period and transitions in experiences of racism across time - were used to evaluate the effects of racism on depressive symptoms. To identify any potential critical period, the effects of frequency of racism, stress of racism, 
Table 1 Creation of the "transitions in experiences of racism" variable from the "frequency and stress" variables for before age 20 (BF20) and during the 20s (DUR20s), as reported by participants

\begin{tabular}{lllll}
\hline Before 20s (BF20) & \multicolumn{2}{l}{ During the 20s (DUR20) } & & \\
\cline { 2 - 5 } "Frequency and Stress" & Never & Low & Moderate & High \\
\cline { 2 - 5 } Never & Stable never & Increasing from never & Increasing from never & Increasing from never \\
Low & Decreasing to never & Stable low (referent) & Increasing & Increasing \\
Moderate & Decreasing to never & Decreasing & Stable moderate & Increasing \\
High & Decreasing to never & Decreasing & Decreasing & Stable high \\
\hline
\end{tabular}

and the combined effect of the frequency and stress related to racism on depressive symptoms at each time period (BF20 and DUR20s) were assessed. Transitions in experiences of racism were assessed with the "Frequency and Stress" racism variables from both time periods (Table 1). All possible combinations of the "Frequency and Stress" racism variable for the two time periods were considered. Some combinations were combined due to limited sample size. The derived transition categories are as follows: (1) Stable Low (referent) - low at both time points; (2) Decreasing - experienced a lower level of the "Frequency and Stress" racism variable DUR20s than BF20 (high to moderate or moderate to low); (3) Increasing - experienced a higher level of "Frequency and Stress" DUR20s than BF20 (moderate to high or low to moderate); (4) Stable Moderate - experienced moderate "Frequency and Stress" in both time periods; (5) Stable High — experienced high "Frequency and Stress" in both time periods; (6) Stable Never - reported never experiencing racism at both time periods; (7) Increasing from Never never experienced racism BF20 and experienced any level of the "Frequency and Stress" variable DUR20s; (8) Decreasing to Never - experienced any level of "Frequency and Stress" variable BF20 but then did not experience the "Frequency and Stress" DUR20s.

\section{Assessment of Depressive Symptoms}

The 11-item, short-form Iowa version of the Center for Epidemiologic Studies-Depression Scale (CESD) developed for the purpose of identifying individuals at high risk for depression was modified for this study [40]. The CES-D items assessed the frequency of the following during the last week: did not feel like eating, felt depressed, felt lonely, felt sad, felt people disliked them, could not get going, felt that everything was an effort, had restless sleep, was happy, enjoyed life, and felt people were unfriendly to them. Participants answered these questions on a Likert scale: always (4), often (3), sometimes (2), hardly ever (1), never (0), and positive questions (e.g., feeling happy, enjoying life) were reverse coded. Using previously published guidelines for the 11-item scale, the items were summed and a cut-point of at least 9 was used to denote high depressive symptoms [41-43]. Majority of participants $(82 \%)$ completed the CES-D scale during the first follow-up with the remaining providing data at follow-up $2(6 \%)$ and follow-up $3(2 \%)$. Of the 1693 participants, 79 were excluded because they did complete a follow-up visit, and 2 returned for a follow-up visits but did not complete the CES-D questions, leaving data from 1612 participants for analyses.

\section{Covariates and Effect Modification Variables}

Based on the literature, covariates used for adjustments were determined using a minimally sufficient set of covariates identified with a directed acyclic graph (DAG) and included those that were more strongly associated with the exposure and outcome than covariates in other minimally sufficient sets. In assessing the association between racism BF20 and CES-D, the adjustment set was family income while growing up (poor, low income, middle income, and well off). For the association between racism DUR20s and CES-D, current annual household income ( $<\$ 20,000, \$ 20,000-50,000,>\$ 50,000)$, employment status (employed, unemployed), and racism before age 20 were included in the model. Information on annual household income and employment status was collected at each study visit, and we utilized the data 
reported during the follow-up visit when CES-D was assessed.

Childhood supportive environment and adult social support were evaluated as potential modifiers of the association between racism and depressive symptoms. Two questions (i.e., family believed in them and family made them feel special) with a response scale ranging from none of the time (0) to all of the time (5) (range: 0 to 10; median: 10) were summed to create the childhood supportive environment. High childhood supportive environment was categorized using the upper 75 th percentile $(>8)$ since the variable was highly left skewed, and low childhood supportive environment was categorized as the lower three quartiles $(\leq 8)$. Two questions with response options ranging from none of the time (0) to all of the time (5) were summed to assess adult social support: (1) Do you have someone who you can count on for emotional support?, and (2) Do you have someone you can count on for help? Using the median as the cut-point, adult social support was defined as high $(>8)$ and low $(\leq 8)$.

\section{Statistical Analysis}

Statistical analyses were performed in $\mathrm{R}$ (Version 3.6.3; www.r-project.org). Numerical variables were summarized with mean and standard deviation (SD) and frequencies and percentages were calculated for categorical variables. The associations between each measure of racism and high depressive symptoms (CES-D scores 9 or higher) were assessed using logistic regression models to calculate crude and adjusted odds ratios that were then converted to crude and adjusted risk ratios with $95 \%$ confidence intervals using the sjstats package in R. To assess the potential modifying effects of childhood supportive environment and adult social support on the association between the "Frequency and Stress" racism variable and depressive symptoms, we performed likelihood ratio tests (LRT) of nested models with interaction terms to obtain $p$-values for assessing statistical significance, and we also conducted stratified analyses.

\section{Results}

The mean baseline age for the 1612 participants was 29 years $(S D=3.4)$ and $36.5 \%$ had high CES-D during follow-up (Table 2). About a third of study participants had a bachelor's degree or higher, with almost $15 \%$ reporting a high school education or less. Only $17 \%$ of participants had an annual household income of more than $\$ 50,000$, with $45 \%$ reporting annual incomes less than $\$ 20,000$. Forty percent of the participants reported being raised in a poor or low-income home as a child. Forty-five percent of the participants had never been married or lived as married, while $38 \%$ reported being married or living as married. Most participants $(71 \%)$ were non-smokers and $19 \%$ were heavy drinkers (i.e., they drank six or more drinks on days when they drank or drank four or more drinks per sitting at least two to three times a month). Fifty-eight percent of the participants reported receiving high social support as an adult, and $81 \%$ of participants reported being raised in a supportive environment.

In both time periods, about $22 \%$ of the participants reported experiencing racism some of the time. The percentage of participants who reported never experiencing racism was similar before age 20 (BF20) (35\%) and in the 20s (DUR20s) (32\%) (Fig. 1). Among those who reported experiences of racism, about half reported mild stress in each of the two time periods, and the percentage reporting severe stress was small - both BF20 (3.9\%) and DUR20s (2.5\%). Considering the "Frequency and Stress" of racism, the percentages of participants classified in the low (20\%) and high (18\%) racism groups were similar across both time periods with the highest percentage among those in the moderate racism group (26\% of women BF20 and 28\% DUR20s).

Before age 20, participants who experienced high frequency racism had an increased risk for high depressive symptoms (CES-D scale score of 9 or higher) (adjusted $\mathrm{RR}=1.26$, 95\% CI: 1.07, 1.46) compared to participants in the low racism frequency group (Table 3). Furthermore, those classified as high stress from racism BF20 had an increased risk of high CES-D than those with low stress (adjusted $\mathrm{RR}=1.30,95 \% \mathrm{CI}: 1.06,1.54)$. During the 20s, there was little evidence of an association for the frequency of racism (adjusted $\mathrm{RR}=1.06,95 \% \mathrm{CI}=0.86,1.27$ ) and the stress due to racism (adjusted $\mathrm{RR}=1.05$, 95\% CI: 0.81, 1.30) with CES-D. For participants experiencing high "Frequency and Stress" of racism BF20 (i.e., experienced racism some or most of the time and reported at least mildly stressful), the risk of 
Table 2 Characteristics of young Black women aged 23-34 years. Study of Environment, Lifestyle, and Fibroids (SELF), 2010 $2012, N=1612$

\begin{tabular}{|c|c|}
\hline Characteristics & $N(\%)$ or mean (DS) \\
\hline High depressive symptoms (CES-D score $\geq 9$ ) & $589(36.5)$ \\
\hline Mean CES-D score & $7.4(5.0)$ \\
\hline Mean age & $29.2(3.4)$ \\
\hline \multicolumn{2}{|l|}{ Highest education } \\
\hline High school/GED or less & $233(14.5)$ \\
\hline Some college/associate's degree/technical training & $827(51.3)$ \\
\hline Bachelor's/master's degree/doctorate or professional degree & $552(34.2)$ \\
\hline \multicolumn{2}{|l|}{ Current household income } \\
\hline$<\$ 20 \mathrm{~K}$ & $722(45.1)$ \\
\hline$\$ 20-\$ 50 \mathrm{~K}$ & $606(37.9)$ \\
\hline$>\$ 50 \mathrm{~K}$ & $272(17.0)$ \\
\hline \multicolumn{2}{|l|}{ Income while growing up } \\
\hline Poor & $75(4.7)$ \\
\hline Low income & $571(35.4)$ \\
\hline Middle income & $846(52.5)$ \\
\hline Well off & $119(7.4)$ \\
\hline \multicolumn{2}{|l|}{ Marital status } \\
\hline Never married or lived as married & $725(45.0)$ \\
\hline Previously married or lived as married & $271(16.8)$ \\
\hline Currently married or living as married & $616(38.2)$ \\
\hline \multicolumn{2}{|l|}{ Smoking status } \\
\hline Never & $1138(70.6)$ \\
\hline Former & $114(7.1)$ \\
\hline Current & $360(22.3)$ \\
\hline \multicolumn{2}{|l|}{ Current alcohol intake } \\
\hline Light & $471(29.2)$ \\
\hline Moderate & $829(51.4)$ \\
\hline Heavy & $312(19.4)$ \\
\hline \multicolumn{2}{|l|}{ Social support as adult } \\
\hline High & $937(58.1)$ \\
\hline Low & 675 (41.9) \\
\hline \multicolumn{2}{|l|}{ Childhood supportive environment } \\
\hline High & $1298(80.6)$ \\
\hline Low & $314(19.5)$ \\
\hline
\end{tabular}

high CES-D was higher compared to those with low "Frequency and Stress" racism (adjusted $\mathrm{RR}=1.38$, 95\% CI: 1.13, 1.64). A positive but somewhat weaker association was also found for high "Frequency and Stress" racism compared with low "Frequency and Stress" racism DUR20s (adjusted RR: 1.21, 95\% CI: $0.93,1.51)$.

There was no evidence for effect modification by adult social support $(p$-value $=0.4)($ Table 3$)$. However, there was suggestive evidence of effect modification by childhood supportive environment on the association between the "Frequency and Stress" of racism and high CES-D ( $p$-value $=0.06)($ Table 3$)$. Among high childhood support, both no experience and high experience of racism BF20 were associated with increased risk of depressive symptoms. A weak dose response in the risk of depressive symptoms across the exposure categories (no experience of racism to high experience of racism) was observed in the low childhood support group.

When examining transitions in experiences of racism from childhood to young adulthood, "stable high" 




Fig. 1 Distribution of the frequency and stress of racism and their combined effect before age 20 and during the 20s among young Black women aged 23-34 year. Study of Environment, Lifestyle, and Fibroids (SELF), 2010-2012

had an increased risk for high depressive symptoms compared to "stable low" (reference group) (adjusted $\mathrm{RR}=1.49,95 \% \mathrm{CI}=1.14,1.86$ ). This was the strongest association among all the transitional patterns (Table 4). The other pattern that was strongly associated with depressive symptoms was "decreasing" (adjusted $\mathrm{RR}=1.44,95 \% \mathrm{CI}=1.08,1.83$ ).

\section{Discussion}

In this prospective cohort study of young Black women in the Detroit, MI, area, exposure to racism was associated with subsequently reported high depressive symptoms. The strongest associations were for experiences of racism before the age of 20 (BF20). Both increased frequency of racism and higher reported associated stress were important aspects of the positive association with future depressive symptoms. This is consistent with conclusions of previous studies that suggest that the intensity of exposure to racism increases the risk of depression [44-46]. Our findings suggest that racism in childhood and adolescence may be even more harmful to mental health than racism in young adulthood. Our results support findings of other prospective studies that reported an association between racism during adolescence and depressive symptoms [47, 48]. One longitudinal study of Black adolescents found experiences of racism to predict depressive symptoms the following year, with a stronger association among girls in early adolescence than among boys [47]. Several studies have found elevated depressive symptoms among Black Indigenous People of Color (BIPOC) youth in the USA compared with White youth [49, 50]. Research suggests that perception and understanding of racist experiences increase during early adolescence among Black youth, along with an increase in depression rates [47]. While children can perceive some discrimination acts by age 6 , the development of cognitive abilities and social awareness that enable more comprehension and perception of discrimination occurs during adolescence $[47,51]$. 
Table 3 Associations between the frequency and stress of racism and their combined effect across the life course and the risk of high depressive symptoms and the modifying role of received support during childhood and adulthood. Study of Environment, Lifestyle, and Fibroids (SELF) 2010-2012, $n=1612$

\begin{tabular}{|c|c|c|c|c|}
\hline \multirow[t]{2}{*}{ Model } & \multicolumn{2}{|l|}{ Racism before the age of 20} & \multicolumn{2}{|l|}{ Racism during the 20 s } \\
\hline & Crude RR $(95 \%$ CI) & Adjusted RR $(95 \% \mathrm{CI})^{1}$ & Crude RR (95\% CI) & Adjusted RR $(95 \% \mathrm{CI})^{2}$ \\
\hline \multicolumn{5}{|l|}{ Frequency of racism } \\
\hline High & $1.27(1.09,1.47)$ & $1.26(1.07,1.46)$ & $1.16(0.98,1.34)$ & $1.06(0.86,1.27)$ \\
\hline Low (referent) & 1.00 & 1.00 & 1.00 & 1.00 \\
\hline Never & $1.08(0.92,1.24)$ & $1.08(0.93,1.25)$ & $1.05(0.90,1.21)$ & $0.95(0.78,1.15)$ \\
\hline \multicolumn{5}{|l|}{ Stress of racism } \\
\hline High stress & $1.33(1.09,1.56)$ & $1.30(1.06,1.54)$ & $1.18(0.96,1.41)$ & $1.05(0.81,1.30)$ \\
\hline Low stress (referent) & 1.00 & 1.00 & 1.00 & 1.00 \\
\hline No stress & $0.90(0.73,1.08)$ & $0.89(0.73,1.07)$ & $0.83(0.68,1.00)$ & $0.84(0.67,1.03)$ \\
\hline \multicolumn{5}{|c|}{ Frequency and stress of racism } \\
\hline High & $1.39(1.14,1.65)$ & $1.38(1.13,1.64)$ & $1.33(1.09,1.58)$ & $1.21(0.93,1.51)$ \\
\hline Moderate & $1.13(0.92,1.36)$ & $1.13(0.91,1.36)$ & $1.16(0.95,1.39)$ & $1.33(1.09,1.58)$ \\
\hline Low (referent) & 1.00 & 1.00 & 1.00 & 1.00 \\
\hline Never & $1.15(0.95,1.37)$ & $1.15(0.95,1.37)$ & $1.16(0.95,1.38)$ & $1.03(0.81,1.29)$ \\
\hline \multicolumn{5}{|c|}{ Frequency and stress of racism by social support } \\
\hline & \multicolumn{2}{|c|}{ Childhood supportive environment RR $(95 \% \mathrm{CI})^{3}$} & \multicolumn{2}{|l|}{ Adult support RR $(95 \% \mathrm{CI})^{4}$} \\
\hline & High & Low & High & Low \\
\hline High & $1.37(1.08,1.69)$ & $1.29(0.91,1.61)$ & $1.20(0.76,1.78)$ & $1.15(0.86,1.42)$ \\
\hline Moderate & $1.04(0.80,1.32)$ & $1.22(0.87,1.54)$ & $1.31(0.91,1.81)$ & $0.96(0.71,1.21)$ \\
\hline Low (referent) & 1.00 & 1.00 & 1.00 & 1.00 \\
\hline Never & $1.21(0.97,1.49)$ & $0.89(0.59,1.23)$ & $1.10(0.74,1.58)$ & $1.00(0.75,1.26)$ \\
\hline
\end{tabular}

\footnotetext{
${ }^{1}$ Adjusted for childhood income

${ }^{2}$ Adjusted for current household income, employment status, and racism before age 20 (included racism variable corresponding to the racism during 20 s variable, e.g., frequency before age 20 and during the 20 s)

${ }^{3}$ Test of homogeneity for interaction between racism before the $20 \mathrm{~s}$ and childhood supportive environment: Likelihood ratio test $(\mathrm{LRT})=7.28(p$-value $=0.06)$

${ }^{4}$ Test of homogeneity for interaction between racism during the 20 s and adult support: $\mathrm{LRT}=2.73(p$-value $=0.4)$
}

Table 4 Risk ratios and 95\% confidence intervals (95\% CI) for the associations of child to adult transitions in the experience of racism with the risk of high depressive symptoms. Study of Environment, Lifestyle, and Fibroids, 2010-2012, $N=1612$

\begin{tabular}{lll}
\hline $\begin{array}{l}\text { Child to adult transitions in } \\
\text { experiences of racism }\end{array}$ & $N$ & $\begin{array}{l}\text { Adjusted risk ratios } \\
\text { (95\% confidence interval) }\end{array}$ \\
\hline Stable high & 190 & $1.49(1.14,1.86)$ \\
Stable moderate & 240 & $1.15(0.85,1.49)$ \\
Stable never & 407 & $1.08(0.82,1.39)$ \\
Increasing from never & 156 & $1.30(0.95,1.69)$ \\
Decreasing to never & 116 & $1.27(0.90,1.69)$ \\
Increasing & 158 & $1.23(0.89,1.61)$ \\
Decreasing & 164 & $1.44(1.08,1.83)$ \\
Stable low & 181 & $1.00($ ref $)$ \\
\hline
\end{tabular}

${ }^{1}$ Models were adjusted for current income and employment status
The transition of childhood-adolescence to young adulthood is challenging for many individuals, especially Black youth, because they may no longer have the family protections that might have shielded them from racism. Surprisingly, young BIPOC adults whose families prepared them for bias and discrimination have been found to have more depressive symptoms than young adults whose parents did not openly discuss race or racism, perhaps a protective parental act [52-54]. In a study of Black women in Detroit, MI, the authors reported an association between a change in the frequency of discrimination over time and the change in depressive symptoms over time [23]. In our study, of the various transitional patterns of the "Frequency and Stress" racism variable, the strongest associations with high depressive 
symptoms were among those who reported stable high racism (i.e., high overall racism at both time points) or decreasing racism compared with stable low racism, suggesting that the most important exposure was racism BF20.

Our findings of the benefit of psychosocial resources on mental health were inconsistent with some of the studies included in a 2009 meta-analysis and another study that found social support to buffer the association between discrimination and mental health in adults by improving coping mechanisms [21, 30]. Hence, we found no evidence for effect measure modification by adult social support. However, there was a suggestion of effect modification by childhood supportive environment ( $p$-value for interaction $=0.06$ ), but both groups reported increased depressive symptoms if they had high experiences of racism $\mathrm{BF} 20$ and the effect was slightly stronger among participants who had experienced high childhood support. The lack of clear benefit from the psychosocial resources evaluated may reflect their insufficiency in ameliorating the reality and anguish of racism. Measurement may be another reason for the lack of buffering because each psychosocial resource variable was assessed with only two items. Furthermore, social support takes on many forms - emotional, instrumental, informational, and appraisal, but we only assessed an aspect of emotional and tangible supports. With $80 \%$ of the participants reporting growing up in a supportive childhood environment, the opportunity for us to detect a strong buffering effect was limited.

A strength of this study was its depth in assessing perceived racism that went beyond an ever and never exposure dichotomy. We assessed the frequency, stress, and the combined effect of the two in two life stages as well as examined the transitions of the experience(s) across time periods. Not only did the results show a stronger association across all measures for the before 20 s life stage, but we also found that the effect in each life stage was stronger when we assessed the combined effect of frequency and stress. This suggests that the frequency of racist events alone may not be sensitive enough to capture the harm of racism, and a combination of frequency and related stress may be more appropriate for assessing the effects of racism on health outcomes.

Another strength of the study was its prospective study design whereby the exposure was obtained prior to the assessment of depressive symptoms. Yet, CES-D was assessed at one time, change in symptoms could not be evaluated. Additionally, we used a modified version of the 11-item CES-D Iowa version that has been validated in the Black population [43]. Despite the CES-D inability to diagnose clinical depression, the scale is practical and has been used in large epidemiologic studies to assess those who are highest risk for depression whereby the administration of a more structured clinical interview is not feasible [55]. Another limitation is that the scale asks about recent depressive symptoms which may be acute due to some life event rather than symptomatic of depression as a mental health condition.

Our data on exposure to racism also have limitations. Data on experiences of racism, BF20 and DUR20s, was collected at baseline using a single question to assess frequency of racism in general and to assess stress resulting from racism. Therefore, there is potential for recall bias. Furthermore, the single-item questions did not permit us to consider domains in which the racism occurred (e.g., school, work, medical care). Such data would enhance the findings by providing information more relevant for developing structural interventions needed to eradicate racism in institutions [56-58]. Our assessment of just the participants' overall and salient experiences of racism may lead to overreporting or underreporting.

It is also important to point out that the data on racism and depressive symptoms for this study was collected at a time unlike today when overt acts of racism have galvanized the attention of all Americans. Thus, it is reasonable to speculate that if SELF had been conducted in 2020 instead of being initiated between 2010 and 2012, the reporting of frequency and stress of racism as well as scores on the CES-D scale would likely be higher because of recent overt racist incidents in public view. Additionally, as Detroit, MI, is one of the most segregated cities in the USA and is majority Black, [59] the report of high frequency of racism here may be lower than that experienced by Black Americans in other cities due to limited opportunities to confront blatant White-on-Black racism in Detroit. Instead, participants in this study and other Black residents in Detroit may experience more structural racism than interpersonal racism (participants may have 
only accounted for interpersonal racism experiences when answering the questions). Detroit residents also face various challenges from the city's eroding economy, high poverty rates, and low education attainment scores [60, 61]. The health of women living in Detroit cannot be separated from the erosion of their physical, emotional, social, economic, and political environments; however, this study assessed individual-level experiences of racism instead of the effects of structural racism. Although the social, economic, and demographic factors in Detroit may be unique, the importance of early-life racism seen in this single geographic area may be broadly generalizable to young Black women in other geographical settings, an age group in which racism has not been well studied.

In summary, the high prevalence of racism and its association with symptoms of depression adds to previously published research [5, 19-23]. Results were stronger for experiences of racism before age 20 than during the 20s. More research grounded in life-course theory is needed to elucidate the effects of early life exposure to racism if the persistent disparities in physical and mental health are to be eliminated. However, the literature to date furthers the call for interventions to redress racism at all levels in the USA.

Acknowledgements This research was funded primarily by an administrative supplement to the parent grant, "Environmental risk factors for uterine fibroids: a prospective ultrasound study (Project\# R01ES028235-03S1)," from the extramural program of the National Institute of Environmental Health Sciences. The research was also supported in part by the Uterine Leiomyomas research program (Project\# ZIAES049013) in the Intramural Research Program of the National Institute of Health, National Institute of Environmental Health Sciences. Funding also came from the American Recovery and Reinvestment Act funds designated for National Institute of Health. We also acknowledge the contributions of the Study of Environment, Lifestyle, and Fibroids (SELF) participants and staff.

\section{References}

1. Major Depression. Natl Inst Ment Heal. 2019. Retrieved July 23, 2021 from https://www.nimh.nih.gov/health/ statistics/major-depression, accessed 23 July 2021.

2. Rodic D, Meyer AH, Meinlschmidt G. The association between depressive symptoms and physical diseases in Switzerland: a cross-sectional general population study. Front Public Heal. 2015;3:1-8.
3. Nierenberg AA, Rapaport MH, Schettler PJ, Howland RH, Smith JA, Edwards D, Schneider T, Mischoulon D. Deficits in psychological well-being and quality-of-life in minor depression: implications for DSM-V. CNS Neurosci Ther. 2010;16:208-16.

4. Simpson SM, Krishnan LL, Kunik ME, Ruiz P. Racial disparities in diagnosis and treatment of depression: a literature review. Psychiatr Q. 2007;78:3-14.

5. Nadimpalli SB, James BD, Yu L, Cothran F, Barnes LL. The association between discrimination and depressive symptoms among older African Americans: the role of psychological and social factors. Exp Aging Res. 2015;41:1-24.

6. Walker Taylor JL, Campbell CM, Thorpe RJJ, Whitfield KE, Nkimbeng M, Szanton SL. Pain, racial discrimination, and depressive symptoms among African American women. Pain Manag Nurs Off J Am Soc Pain Manag Nurses. 2018;19:79-87.

7. Yoon E, Coburn C, Spence SA. Perceived discrimination and mental health among older African Americans: the role of psychological well-being. Aging Ment Health. 2019;23:461-9.

8. Lambert SF, Herman KC, Bynum MS, Ialongo NS. Perceptions of racism and depressive symptoms in African American adolescents: the role of perceived academic and social control. J Youth Adolesc. 2009;38:519-31.

9. Jackson FM, James SA, Owens TC, Bryan AF. Anticipated negative police-youth encounters and depressive symptoms among pregnant African American women: a brief report. J Urban Health. 2017;94:259-65.

10. Jones C. Confronting institutionalized racism. Phylon. 2002;50:7-22.

11. Jones CP. Levels of racism: a theoretic framework and a gardener's tale. Am J Public Health. 2000;90:1212-5.

12 Jee-Lyn García J, Sharif MZ. Black lives matter: a commentary on racism and public health. Am J Public Health. 2015;105:e27-30.

13. Phelan JC, Link BG. Is racism a fundamental cause of inequalities in health? Annu Rev Sociol. 2015;41:311-30.

14. Williams DR. Race, socioeconomic status, and health the added effects of racism and discrimination. Ann N Y Acad Sci. 1999;896:173-88.

15. Williams DR, Lawrence JA, Davis BA, Vu C. Understanding how discrimination can affect health. Health Serv Res. 2019;54(Suppl 2):1374-88.

16. Williams DR, Lawrence JA, Davis BA. Racism and health: evidence and needed research. Annu Rev Public Health. 2019;40:105-25.

17. Paradies Y, Ben J, Denson N, Elias A, Priest N, Pieterse A, Gupta A, Kelaher M, Gee G. Racism as a determinant of health: a systematic review and meta-analysis. PLoS One. 2015;10:e138511.

18. Webb Hooper M, Nápoles AM, Pérez-Stable EJ. COVID-19 and racial/ethnic disparities. JAMA. 2020;323:2466-7.

19. Wheaton FV, Thomas CS, Roman C, Abdou CM. Discrimination and depressive symptoms among African American men across the adult lifecourse. J Gerontol B Psychol Sci Soc Sci. 2018;73:208-18. 
20. Li LW, Dong X. Self-reported discrimination and depressive symptoms among older chinese adults in Chicago. $\mathrm{J}$ Gerontol A Biol Sci Med Sci. 2017;72:S119-24.

21. Pascoe EA, Smart RL. Perceived discrimination and health: a meta-analytic review. Psychol Bull. 2009;135:531-54.

22. Janzen B, Karunanayake C, Rennie D, Katapally T, Dyck R, McMullin K, Fenton M, Jimmy L, MacDonald J, Ramsden VR, Dosman J, Abonyi S, Pahwa P. Racial discrimination and depression among on-reserve First Nations people in rural Saskatchewan. Can J Public Health. 2018;108:e482-7.

23. Schulz AJ, Gravlee CC, Williams DR, Israel BA, Mentz G, Rowe Z. Discrimination, symptoms of depression, and self-rated health among African american women in detroit: results from a longitudinal analysis. Am J Public Health. 2006;96:1265-70.

24. Vines AI, Ward JB, Cordoba E, Black KZ. Perceived racial/ethnic discrimination and mental health: a review and future directions for social epidemiology. Curr Epidemiol reports. 2017;4:156-65.

25. Polanco-Roman L, Anglin DM, Miranda R, Jeglic EL. Racial/ethnic discrimination and suicidal ideation in emerging adults: the role of traumatic stress and depressive symptoms varies by gender not racelethnicity. J Youth Adolesc. 2019;48:2023-37.

26. Carter RT. Racism and psychological and emotional injury: recognizing and assessing race-based traumatic stress. Couns Psychol. 2007;35:13-105.

27. Berger M, Sarnyai Z. "More than skin deep": stress neurobiology and mental health consequences of racial discrimination. Stress. 2015;18:1-10.

28. Walker RL, Salami TK, Carter SE, Flowers K. Perceived racism and suicide ideation: mediating role of depression but moderating role of religiosity among African American adults. Suicide Life Threat Behav. 2014;44:548-59.

29. Odom EC, Vernon-Feagans L. Buffers of racial discrimination: links with depression among rural African American mothers. J Marriage Fam. 2010;72:346-59.

30. Chou K-L. Perceived discrimination and depression among new migrants to Hong Kong: the moderating role of social support and neighborhood collective efficacy. $\mathrm{J}$ Affect Disord. 2012;138:63-70.

31. Schulz AJ, Israel BA, Zenk SN, Parker EA, Lichtenstein R, Shellman-Weir S, Klem ABL. Psychosocial stress and social support as mediators of relationships between income, length of residence and depressive symptoms among African American women on Detroit's eastside. Soc Sci Med. 2006;62:510-22.

32. Pearlin LI, Schieman S, Fazio EM, Meersman SC. Stress, health, and the life course: some conceptual perspectives. J Health Soc Behav. 2005;46:205-19.

33. Surachman A, Wardecker B, Chow S-M, Almeida D. Life course socioeconomic status, daily stressors, and daily well-being: examining chain of risk models. J Gerontol B Psychol Sci Soc Sci. 2019;74:126-35.

34. Kuh D, Ben-Shlomo Y, Lynch J, Hallqvist J, Power C. Life course epidemiology. J Epidemiol Community Health. 2003;57:778-83.

35. Lee DB, Anderson RE, Hope MO, Zimmerman MA. Racial discrimination trajectories predicting psychological well-being: from emerging adulthood to adulthood. Dev Psychol. 2020;56:1413-23.

36. Lazarus R, Folkman S. Stress, appraisal, and coping. New York: Springer; 1984.

37. Barnes PW, Lightsey OR Jr. Perceived racist discrimination, coping, stress, and life satisfaction. J Multicult Couns Devel. 2005;33:48-61.

38. Baird DD, Harmon QE, Upson K, Moore KR, BarkerCummings C, Baker S, Cooper T, Wegienka G. A prospective, ultrasound-based study to evaluate risk factors for uterine fibroid incidence and growth: methods and results of recruitment. J Womens Health (Larchmt). 2015;24:907-15.

39. Vines AI, McNeilly MD, Stevens J, Hertz-Picciotto I, Baird M, Baird DD. Development and reliability of a Telephone-Administered Perceived Racism Scale (TPRS): a tool for epidemiological use. Ethn Dis. 2001;11:251-62.

40. Radloff LS. The CES-D scale: a self-report depression scale for research in the general population. Appl Psychol Meas. 1977;1:385-401.

41. Kohout FJ, Berkman LF, Evans DA, Cornoni-Huntley J. Two shorter forms of the CES-D (Center for Epidemiological Studies Depression) depression symptoms index. J Aging Health. 1993;5:179-93.

42. Carpenter J, Andrykowski M, Wilson J, Hall L, Kay Rayens M, Sachs B, Cunningham L. Psychometrics for two short forms of the Center for Epidemiologic Studies-Depression Scale. Issues Ment Health Nurs. 1998;19:481-94.

43. Torres E. Psychometric properties of the Center for Epidemiologic Studies Depression Scale in African American and Black Caribbean US adults. Issues Ment Health Nurs. 2012;33:687-96.

44 Wallace S, Nazroo J, Bécares L. Cumulative effect of racial discrimination on the mental health of ethnic minorities in the United Kingdom. Am J Public Health. 2016;106:1294-300.

45. Priest N, Kavanagh A, Bécares L, King T. Cumulative effects of bullying and racial discrimination on adolescent health in Australia. J Health Soc Behav. 2019;60:344-61.

46. Bécares L, Zhang N. Perceived interpersonal discrimination and older women's mental health: accumulation across domains, attributions, and time. Am J Epidemiol. 2018;187:924-32.

47. English D, Lambert SF, Ialongo NS. Longitudinal associations between experienced racial discrimination and depressive symptoms in African American adolescents. Dev Psychol. 2014;50:1190-6.

48. Brody GH, Chen Y-F, Murry VM, Ge X, Simons RL, Gibbons FX, Gerrard M, Cutrona CE. Perceived discrimination and the adjustment of African American youths: a five-year longitudinal analysis with contextual moderation effects. Child Dev. 2006;77:1170-89.

49. Anderson ER, Mayes LC. Race/ethnicity and internalizing disorders in youth: a review. Clin Psychol Rev. 2010;30:338-48.

50. Brown JS, Meadows SO, Elder GH. Race-ethnic inequality and psychological distress: depressive symptoms from adolescence to young adulthood. Dev Psychol. 2007;43:1295-311. 
51. Spears Brown C, Bigler RS. Children's perceptions of discrimination: a developmental model. Child Dev. 2005;76:533-53.

52. Liu LL, Lau AS. 2013. Teaching about race/ethnicity and racism matters: an examination of how perceived ethnic racial socialization processes are associated with depression symptoms. Cult Divers Ethn Minor Psychol. Educational Publishing Foundation, Liu, Lisa L.: 1285 Franz Hall, Box 951563, Los Angeles, CA, US, 90095-1563, lisaliu@psych.ucla.edu.

53. Osborne KR, Caughy MO, Oshri A, Smith EP, Owen MT. 2020. Racism and preparation for bias within African American families. Cultur Divers Ethnic Minor Psycholhttps://doi.org/10.1037/cdp0000339

54. Park IJK, Du H, Wang L, Williams DR, Alegría M. The role of parents' ethnic-racial socialization practices in the discrimination-depression link among Mexicanorigin adolescents. J Clin child Adolesc Psychol Off J Soc Clin Child Adolesc Psychol Am Psychol Assoc Div. 2020;53(49):391-404.

55. Wise LA, Adams-Campbell LL, Palmer JR, Rosenberg L. Leisure time physical activity in relation to depressive symptoms in the Black Women's Health Study. Ann Behav Med. 2006;32:68-76.

56. Williams DR, Mohammed SA. Racism and health II: a needed research agenda for effective interventions. Am Behav Sci. 2013;57:1200-26.
57. Brown AF, Ma GX, Miranda J, Eng E, Castille D, Brockie T, Jones P, Airhihenbuwa CO, Farhat T, Zhu L, Trinh-Shevrin C. Structural interventions to reduce and eliminate health disparities. Am J Public Health. 2019;109:S72-8.

58. Bailey ZD, Krieger N, Agénor M, Graves J, Linos N, Bassett MT. Structural racism and health inequities in the USA: evidence and interventions. Lancet (London, England). 2017;389:1453-63.

59. Menendian S, Arthur G, Gambhir S. 2021. The roots of structural racism project: twenty-first century racial residential segregation in the United States. Berkeley, CA.

60. Percent of people living below the poverty line. American Community Survey, 2019. https://www.census.gov/quick facts/fact/table/detroitcitymichigan/PST120219, accessed 22 July 2021.

61. Einborn, E. 10 April 2018. Detroit schools ranked worst on national exam--again. But is there hope that things can improve? Chalkbeat Detroit. https://detroit.chalkbeat.org/ 2018/4/10/21104741/detroit-schools-ranked-worst-onnat ional-exam-again-but-is-there-hope-that-things-can-impro ve, accessed 22 July 2021.

Publisher's Note Springer Nature remains neutral with regard to jurisdictional claims in published maps and institutional affiliations. 